\title{
Evaluation of Aerosol Contamination during Ultrasonic Procedures
}

\author{
Dr. Neha Verma, ${ }^{1}$ Dr. Dhritiman Baidya, ${ }^{2}$ Dr. Barkha Makhijani, ${ }^{3}$ Dr. Neema Shetty, ${ }^{4}$ \\ Dr. Aditi Mathur, ${ }^{5}$ Dr. Balaji Manohar ${ }^{6}$ \\ ${ }^{1,2}$ Resident, ${ }^{3}$ Senior lecturer, ${ }^{4,5}$ Reader, ${ }^{6}$ Professor and Head, Department of Periodontics \\ Pacific Dental College and Hospital, Udaipur, India
}

\begin{abstract}
Background: Operator safety during dental \& periodontal treatment is a non-negotiable necessity. The production of airborne material, during dental procedures is obvious to the dentist, dental team and the patient.

Aim: The aim of the present study was to evaluate, the colony forming units (CFU) generated from aerosol during ultrasonic procedure in gingivitis and periodontitis subjects that act as a potential risk factor for spread of infectious agents for both operator and patients.

Materials and Methods: The present study included 18 subjects which were randomly assigned into 3 equal groups. Group I (Control group) subjects were treated with ultrasonic scaling alone, whereas; Groups II \& Group III (Test groups) subjects used pre-procedural mouthrinses before scaling \& root planing (Chlorhexidine and Povidone Iodine). Blood agar plates were used to assess the aerosol contamination and were placed at operator's eye level, subject's eye \& chest level. These plates were then incubated for 72 hours and microbial growth were quantified as colony forming units (CFU/plate). Different colonies were identified by standard biochemical methods.

Results: This study showed that the antiseptic mouthrinses significantly reduce the bacterial CFU in the aerosol. Povidone Iodine was found to be superior to Chlorhexidine when used pre-procedurally.

Conclusion: The following conclusion was drawn that the use of pre-procedural rinses significantly reduced the aerosol contamination and hence chances of cross-infection in the dental units.

Key Words: Chlorhexidine, povidone iodine, blood agar plates, aerosols, colony forming units
\end{abstract}

\section{INTRODUCTION}

Modern dentistry is founded upon a preventive philosophy in which subjects are encouraged to attend regular examination. ${ }^{1}$ Potential problems may be detected at an early stage and appropriate action taken before they become more serious. Treatment of periodontal diseases primarily aims towards the reduction of embedded microorganism in the sub-gingival biofilm. Mechanical debridement of the periodontal pocket has been demonstrated to significantly improve gingival health. ${ }^{2}$ Although, there is limited evidence of clinical efficacy and safety, there is a strong trend among clinicians to give preference to ultrasonic instruments for subgingival debridement. ${ }^{3}$

\section{Correspondence:}

Dr. Neha Verma

Department of Periodontics, Pacific Dental College and Hospital, Udaipur, India

email: nehavarma_0731@yahoo.com

\section{Citation}

Verma N, Baidya D, Makhijani B, Shetty N, Mathur A, Manohar B. Evaluation of aerosol contamination during ultrasonic procedures.

J Nep Soc Perio Oral Implantol. 2017;1:17-22.
Many routine dental procedures produce aerosol and splatter composed of various combinations of water like organic particles, such as tissue and tooth dust; and organic fluids, such as blood and saliva. ${ }^{4}$ They also contain bacteria (streptococci and staphylococci), protozoa, fungi and blood borne viruses..$^{5,6}$ The terminology, "aerosol and splatters" in dental environment were proposed by Micik and collegues ${ }^{7-11}$ in their pioneering work on aerobiology. They defined aerosol "as suspensions of liquid and/or solid particles in the air generated by coughing, sneezing, or any other act that expels oral fluids into the air (particle size is 50 micrometers)". The smaller particles of an aerosol ( 0.5 to $10 \mu \mathrm{m}$ in diameter) have the potential to penetrate and lodge in the smaller passages of the lungs and are thought to carry the greatest potential for transmitting infections. Splatters are defined as "airborne particles larger than $50 \mu \mathrm{m}$ in diameter". They stated that these particles behaved in a ballistic manner. This means that these particles or droplets are ejected forcibly from the operating site and arc in a trajectory similar to that of a bullet until they contact a surface or fall to the floor. Majority of the particles in the aerosol are less than 100 microns. 
The production of airborne material during dental procedures is obvious to the dentist, the dental team and the subject. Dental health professionals, because of repeated exposures to these microorganisms, are at high risk for developing infectious diseases. Transmission of microorganisms from person to person may occur by direct contact with contaminated tissues or instruments or by aerosols containing infectious agents. ${ }^{12,13}$ The major source of potential aerosol contamination in a dental set up is the ultrasonic scaler. As soon as the water spray is emitted from the hand piece of the instrument, it can mix with the subject's saliva and blood present to form a potentially pathogenic aerosol. ${ }^{14}$ Microorganisms which are present in the mouth and respiratory tract can be transported in the aerosol produced during dental procedures leading to respiratory infections, skin infections and other systemic diseases in immunocompromised subject. They also contaminate the mucous membrane of the mouth, respiratory passages, eyes of dental professionals and subjects and the surrounding surfaces. ${ }^{15}$

Hence, the aim of the present study was to evaluate, the CFU generated from aerosol during ultrasonic procedure in gingivitis and periodontitis subjects that act as a potential risk factor for spread of infectious agents for both operator and subjects.

The objective was to compare and evaluate the effectiveness of two commercially available mouthrinses namely Chlorhexidine and Povidone Iodine as a pre-procedural mouthrinses in reducing the number of CFU in aerosol samples.

\section{MATERIALS AND METHODS}

18 subjects who reported to the Department of Periodontics, Pacific Dental College and Hospital, Debari, Udaipur were selected according to the following criteria:

\section{INCLUSION CRITERIA}

1. Presence of full complement of maxillary and mandibular anterior teeth

2. Absence of any dental treatment for past 1 year

3. Subject with plaque and gingival score between 1 and 2 .

\section{EXCLUSION CRITERIA}

1. History of systemic disease, cardiac pacemakers or respiratory complication,

2. Pregnant women

3. Subjects with conditions requiring prophylactic antibiotics, prior to dental procedure and those currently on medication.

Based on the above criteria 18 subjects which were randomly assigned into 3 equal groups. All the procedure was carried out by a single examiner.
- Group I (Control group $\mathrm{n}=6$ ): $0.9 \%$ normal saline was used as a mouth rinse. After 2 minutes of gargle scaling and root planing was performed in maxillary and mandibular anterior region for 30 minutes.

- Group II (Test group n=6): Group II: 0.2\% Chlorhexidine was used as a mouth rinse. After 2 minutes of gargle with Chlorhexidine scaling and root planing was performed in the maxillary and mandibular anterior region for 30 minutes.

- Group III (Test group n=6): 5\% Povidone Iodine (Betadine) was used as a mouth rinse. After 2 minutes of gargle with Betadine scaling and root planing was performed in the maxillary and mandibular anterior region for 30 minutes.

\section{Treatment}

Before starting treatment, a written informed consent was taken from all the participants. Clinical parameters recorded at baseline were Gingival index (Loe and Silness), Plaque index (Silness and Loe), Calculus severity index (Ramjford) and Index of Air Microbial contamination (Pasquarella et al.).

Pasquarella et al. ${ }^{16}$ described the Index of Air Microbial contamination (IMA) based on the count of the microbial fallout on to Petri dishes left open to the air according to the 1/1/1 scheme (for $1 \mathrm{~h}, 1 \mathrm{~m}$ from the floor, at least $1 \mathrm{~m}$ away from walls or any obstacle).

Disinfection of the operatory was done with the help of Fumigator machine and a disinfectant solution. The Operatory was fumigated 24 hours before the treatment. It was then left unused and locked overnight. $10 \mathrm{~min}$ before the treatment, plate 1 was placed at the center of the operatory, to determine if there was any aerosols present in the room. To ensure the room was free from aerosol only one subject was treated per day.

For each subject, three agar plates were exposed during the study. Three standardized locations in the same operatory were chosen to be evaluated for aerosol collection i.e. operator's eye level, subject's eye level and subject's chest level was considered as a parameter in this study as these position determine the risk to the operator and the subject respectively (Figure 1). After fixing the position of agar plate at same predesignated sites for each subject, the three blood agar plates were kept uncovered to collect samples of aerolized bacteria. Piezo electric ultrasonic scaler was used for scaling and root planing. The tip of the instrument was kept in contact with teeth during the entire scaling procedure. Power and supply of the coolant were turned to moderate setting. In this combination a fine water spray was generated at the tip of the device. 


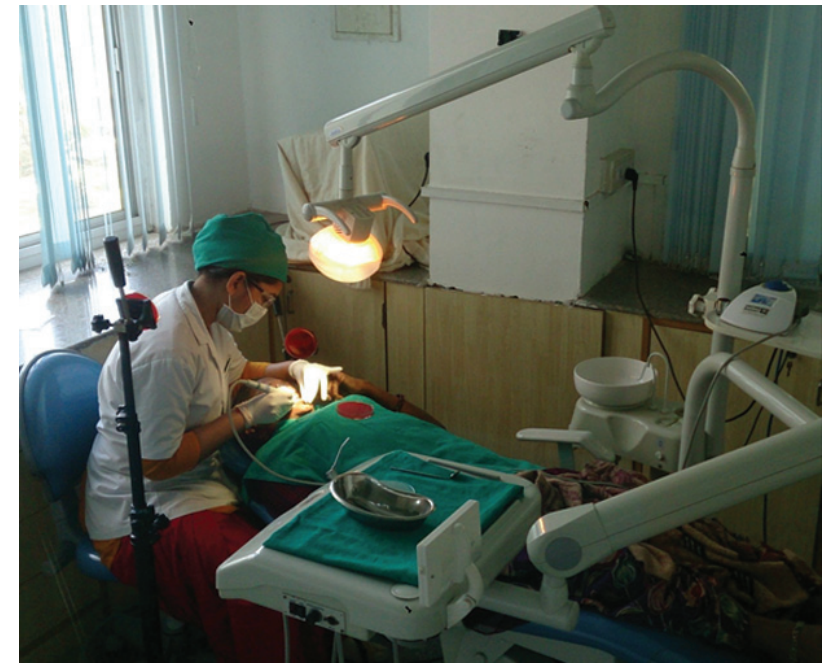

Figure 1: Positioning of Blood agar plates at various levels

After the treatment, the three agar plates which was kept open during procedure were sealed and kept aside. At the end, all the four agar plates were kept in sealed plastic packet and sent to the laboratory for examination. The agar plates were than incubated at the temperature of $37^{\circ} \mathrm{C}$ for 72 hours so that the colonies of micro-organism can grow fully on the agar plate for easy detection.

Statistical analysis was done by using IBM SPSS software v20.0. One way ANOVA was done for intragroup comparison and Post Hoc test for intergroup comparison.

\section{RESULTS}

Results were calculated between the groups at four different levels i.e; Plate1: Preprocedural, Plate 2: Operator's eye level, Plate 3: Subject's eye level, Plate 4: Subject's chest level. Clinical parameters were recorded at baseline to divide the subjects of each group into gingivitis and periodontitis. CFU

Table 1: Comparison of mean of Colony Forming Units

\begin{tabular}{|c|c|c|c|c|c|}
\hline & \multirow[b]{2}{*}{ Groups } & \multirow{2}{*}{$\begin{array}{c}\text { No of } \\
\text { patients }\end{array}$} & \multicolumn{2}{|c|}{ Colony Forming Units } & \multirow{2}{*}{$\begin{array}{c}p \\
\text { value }\end{array}$} \\
\hline & & & Mean & $\begin{array}{l}\text { Standard } \\
\text { Deviation }\end{array}$ & \\
\hline \multirow{3}{*}{ Plate 1} & Group I & 6 & 3.00 & \pm 1.673 & \multirow{3}{*}{0.492} \\
\hline & Group II & 6 & 2.67 & \pm 1.366 & \\
\hline & Group III & 6 & 2.00 & \pm 1.265 & \\
\hline \multirow{3}{*}{ Plate 2} & Group I & 6 & 46.50 & \pm 16.670 & \multirow{3}{*}{0.030} \\
\hline & Group II & 6 & 25.17 & \pm 9.786 & \\
\hline & Group III & 6 & 30.00 & \pm 11.384 & \\
\hline \multirow{3}{*}{ Plate 3} & Group I & 6 & 64.17 & \pm 16.290 & \multirow{3}{*}{0.006} \\
\hline & Group II & 6 & 37.17 & \pm 15.993 & \\
\hline & Group III & 6 & 34.83 & \pm 10.834 & \\
\hline \multirow{3}{*}{ Plate 4} & Group I & 6 & 87.33 & \pm 12.972 & \multirow{3}{*}{0.003} \\
\hline & Group II & 6 & 55.17 & \pm 16.642 & \\
\hline & Group III & 6 & 59.83 & \pm 12.336 & \\
\hline
\end{tabular}

Day 3

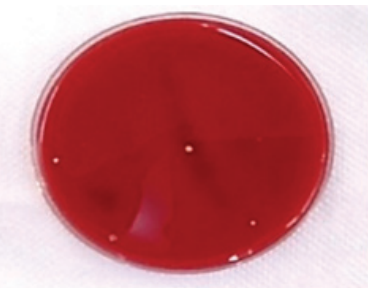

Plate 1

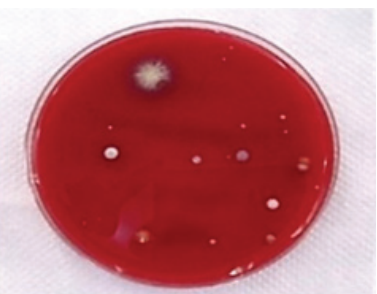

Plate 3

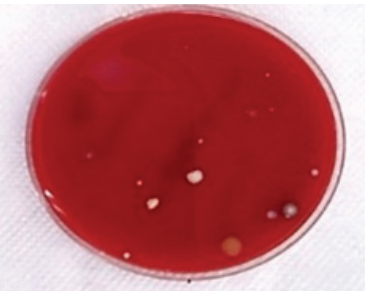

Plate 2

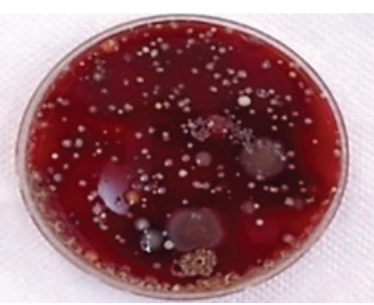

Plate 4
Figure 2: Blood agar plates with bacterial colonies at 72 hours

was calculated after 72 hours in all the four plates (Figure 2)

The CFU values of pre-procedural plate (Plate 1) was compared at baseline for the three groups. The intergroup comparison showed no statistical significant result ( $p=0.492)$ (Table $1 \& 2$, Graph 1$)$.

On comparing the CFU values at operator's eye level (Plate 2), inter-group comparison showed a statistically significant result $(p=0.030)$. On comparing the mean value of Group I with Group II, the result was statistically significant $(p=0.030$ ). Similarly; when values of CFU was compared between Group I with Group III and Group II with Group III, the results was statistically non-significant ( $p=0.10$ and $p=0.79$ respectively). (Table $1 \& 2$, Graph 2 ).

When the CFU values was calculated at the 's eye level (Plate 3), the inter-group comparison showed a statistically significant result ( $p=0.006$ ). On comparing the mean values of Group

Table 2: Inter-Group comparison of Colony Forming Units

\begin{tabular}{|c|l|c|}
\hline \multirow{4}{*}{ Plate 1 } & \multicolumn{1}{|c|}{ Groups } & $\boldsymbol{p}$ value \\
\cline { 2 - 3 } & Group I vs Group II & 0.91 \\
\cline { 2 - 3 } & Group I vs Group III & 0.47 \\
\cline { 2 - 3 } & Group II vs Group III & 0.70 \\
\hline \multirow{4}{*}{ Plate 2 } & Group I vs Group II & 0.03 \\
\cline { 2 - 3 } & Group I vs Group III & 0.10 \\
\cline { 2 - 3 } & Group II vs Group III & 0.79 \\
\hline \multirow{3}{*}{ Plate 4 } & Group I vs Group II & 0.01 \\
\cline { 2 - 3 } & Group I vs Group III & 0.009 \\
\cline { 2 - 3 } & Group II vs Group III & 0.95 \\
\cline { 2 - 3 } & Group I vs Group II & 0.003 \\
\cline { 2 - 3 } & Group I vs Group III & 0.01 \\
\cline { 2 - 3 } & Group II vs Group III & 0.83 \\
\hline
\end{tabular}


Graph 1

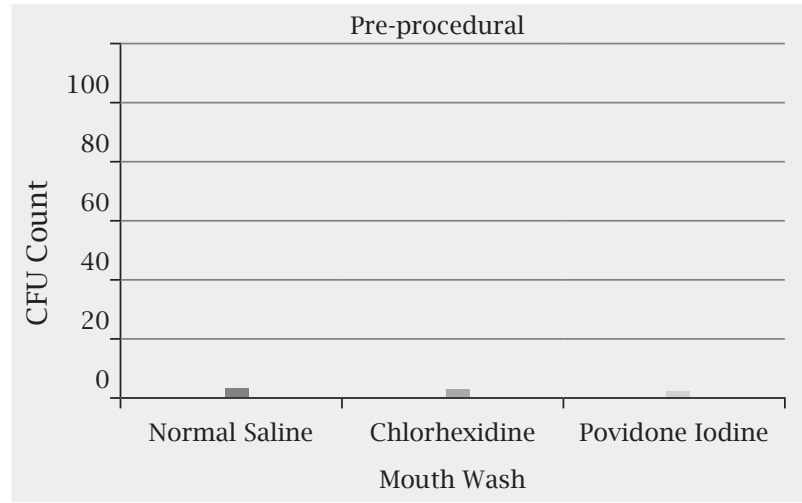

Graph 3

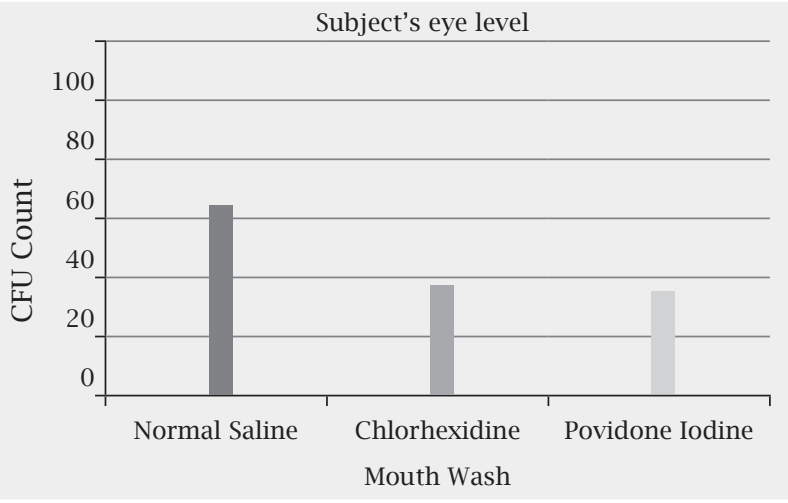

I with Group II and Group I with Group III, the result was statistically significant ( $p=0.01$ and $p=0.009$ respectively). On comparing the values of Group II with Group III, the results was statistically non-significant $(p=0.95)$. (Table 1

\section{\& 2, Graph 3).}

On comparing CFU values at subject's chest level (Plate $4)$, the inter-group comparison showed a statistically significant result $(p=0.003)$. On comparing the mean values of Group I with Group II and Group I with Group III, the result was statistically significant $(p=0.003$ and $p=0.01$ respectively). However; on comparing the values of Group II with Group III, the results was statistically nonsignificant ( $p=0.83)$. (Table $1 \& 2$, Graph 4 ).

\section{DISCUSSION}

The American Dental Association has recommended that potential contaminated aerosols or splatter should be controlled during dental procedures. ${ }^{17}$ While there have been no definitive epidemiologic studies that have linked dental aerosols to disease transmission, the presence of a cloud of contaminated aerosol and splatter, such as that produced by an ultrasonic scaler, should be of concern to the dental practitioner. ${ }^{18}$

This study demonstrates that a sufficient amount of aerosol and splatter from the subject was ejected far enough to
Graph 2

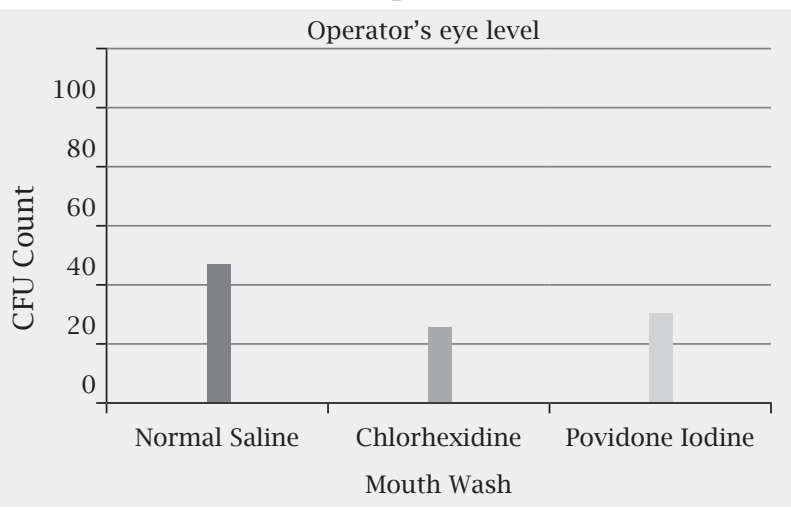

Graph 4

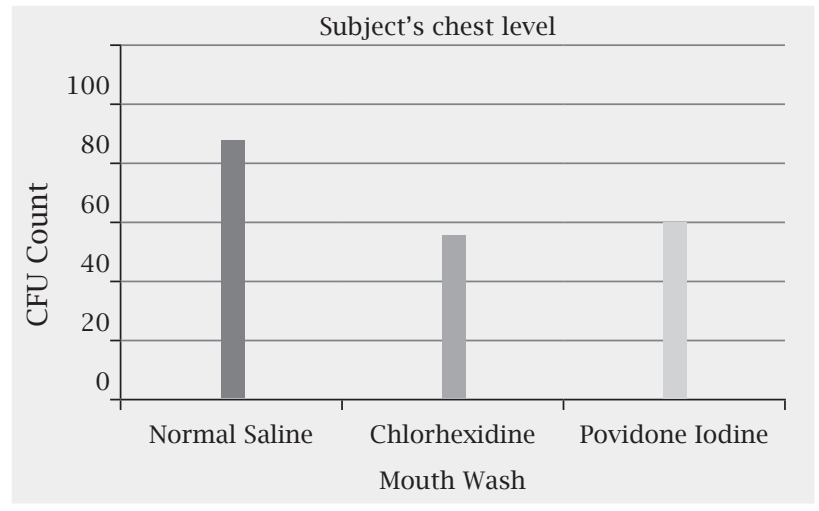

come into contact with dental personnel, dental auxiliary and subjects.

In the present study, an attempt was made to evaluate and compare the ability of different pre-procedural mouth rinses to lower the microbial counts during the use of aerosol producing ultrasonic scalers. Before starting treatment, almost no bacterial contamination of the air in the dental operatory was found. This was in contrast to the results found by Legnani et al. ${ }^{19}$ who found contaminated atmosphere prior to the treatment procedure.

There is a considerable increase in CFU count seen during the procedure. But the result of present study showed that there was a significant reduction of the bacterial CFU in the test groups. The present study showed a significant difference in favor of Chlorhexidine and Povidone Iodine when compared with normal saline. But there was no significant difference between Chlorhexidine and Povidone Iodine. It can also be supported by an early study by Vanderwyk ${ }^{20}$ who noted microbicidal activity of Povidone Iodine showing $72 \%$ reduction for $30 \mathrm{~min}$ after rinsing and the decrease was still 38\% below the pre-rinse count after 90 min. Logothetis and Martinez Welles ${ }^{21}$ also showed that Chlorhexidine pretreatment rinse was effective in reducing bacterial aerosol contamination with the use of air polisher. 
The CFU was maximum at subject's chest level, secondly on subject's eye level and followed by operator's eye level. The highest CFU at the subject's chest position is similar to the findings of Bentley et al. ${ }^{22}$ who observed the larger salivary droplets generated during dental procedures settle rapidly from the air with heavy contamination on the subject's chest. This could be explained because of nearer distance and gravity that plays a role in precipitation of the suspended particles of aerosol.

The present study also demonstrates maximum reduction of aerobic colonies using Povidone Iodine at subject's eye level where as Chlorhexidine exhibited maximum reduction at operator's eye level and subject's chest level. This proves that almost 40-50 \% reduction of bacterial load is achieved by pre-procedural mouth rinses. Subject's eye level is the second area of concern because it is nearest to the mouth after chest level. It has less contamination because it is against gravity and far away from source of contamination. Operator's eye is least affected but it can't be ignored It should be compulsory for both subject and operator to use eye wear, to prevent contamination during dental procedures.
Harrel and Molinari recommend three levels of defense in the reduction of aerosols. ${ }^{23}$ The first recommended layer of defense is personal protective barriers such as mask, gloves and safety glasses. The second layer is routine use of an antiseptic pre-procedural rinse. Chlorhexidine is considered as the "Gold standard" of antimicrobial rinse because of broadspectrum antibacterial activity and substantivity of 8-12 hrs. ${ }^{24,25}$ Povidone Iodine as a pre-procedural rinse effectively reduces gingival surface flora prior to oral prophylaxis with ultrasonic scalers and maintains this reduction throughout the duration of the prophylactic procedure. ${ }^{26}$ The final layer is the use of high evacuation device.

The American Dental Association advocated protective eyewear for dental health personnel and subjects during dental procedures. ${ }^{27}$

\section{CONCLUSION}

The results of the present study must be used for increasing awareness and quantifying the risk of operator and subject exposure to aerosolized microbial pathogens in the general dental office, which must be controlled by efficient preventive measures.

\section{REFERENCES}

1. Chadwick RG, Alatsaris M, Ranka M. Eye care habits of dentists registered in the United Kingdom. Br Dent J. 2007;203(4):1-5.

2. Van der Weijden GA, Timmerman MF. A systematic review on the clinical efficacy of subgingival debridement in the treatment of chronic periodontitis. J Clin Periodontol. 2003;29:55-71.

3. Tunkel J, Heinecke A, Flemmig, TF. A systematic review of efficacy of machine driven and manual subgingival debridement in the treatment of chronic periodontitis. J Clin Periodontol. 2002;29 (Suppl. 3):72-81.

4. Harrel S, Barnes J, Rivera-Hidalgo F. Aerosol and spatter contamination from the operative site during ultrasonic scaling. J Am Dent Assoc. 1998;129:1241-49.

5. Castiglia P, Liguori G, Montagna MT, Napoli C, Pasquarella C, Bergomi M, Fabiani L, Monarca S, Petti S. Italian multicenter study on infection hazards during dental practice: control of environmental microbial contamination in public dental surgeries. BMC Public Health. 2008;8:187-94.

6. Toroglu MS, Haytac MC, Koksal F. Evaluation of aerosol contamination during debonding procedures. Angle Orthod. 2001;71:299-306.

7. Micik RE, Miller RL, Mazzarella MA, Ryge G. Studies on dental aerobiology, I: bacterial aerosols generated during dental procedures. J Dent Res. 1969;48(1):49-56.

8. Miller RL, Micik RE, Abel C, Ryge G. Studies of dental aerobiology, II: microbial splatter discharged from the oral cavity of dental patients. J Dent Res. 1971;50:621-5.

9. Micik RE, Miller RL, Leong AC. Studies on dental aerobiology, 3: efficacy of surgical masks in protecting dental personnel from airborne bacterial particles. J Dent Res. 1971;50:626-30.

10. Abel LC, Miller RL, Micik RE, Ryge G. Studies on dental aerobiology, IV: bacterial contamination of water delivered by dental units. J Dent Res. 1971;50:1567-9.

11. Miller RL, Micik RE. Air pollution and its control in the dental office. Dent Clin North Am. 1978;22:453-76.

12. Lu DP, Zambito RF. Aerosols and cross infection in dental practice-a historic view. Gen Dent. 1981;29:136-43.

13. King TB, Muzzin KB, Berry CW, Anders LM.The effectiveness of an aerosol reduction device for ultrasonic scalers. J Periodontol. 1997;68:45-9.

14. Miller RL. Characteristics of blood-containing aerosols generated by common powered dental instruments. Am Ind Hyg Assoc J. 1995;56:670-6.

15. Fine D, Mendieta C. Efficacy of pre-procedural rinsing with an antiseptic in reducing viable bacteria in dental aerosols. J Periodontol. 1992;63:821-4.

16. Pasquarella C, Pitzurra O, Savino A. The index of microbial air contamination. J Hosp Infect. 2000;46:241-56.

17. Infection control recommendations for the dental office and the dental laboratory. ADA Council on Scientific Affairs and ADA Council on Dental Practice. J Am Dent Assoc. 1996;127:672-80.

18. Araujo MW, Andreana S. Risk and prevention of transmission of infectious diseases in dentistry. Quintessence Int. 2002;33:376-82. 
19. Legnani P, Checchi L, Pelliccioni GA, D’Achille C. Atmospheric contamination during dental procedures. Quintessence Int. 1994;25:435-9.

20. Vanderwyk RW. Killing efficiency of povidone iodine, in vivo and in vitro studies of microbicidal activity. Miami Beach, Florida: Am Dent Assoc; October 1968.

21. Logothetis DD, Martinez-Welles JM. Reducing bacterial aerosol contamination with a chlorhexidine gluconate pre-rinse. J Am Dent Assoc. 1995;126:1634-9.

22. Bentley CD, Burkhart NW, Crawford JJ. Evaluating spatter and aerosol contamination during dental procedures. J Am Dent Assoc. 1994;125:579-84.

23. Harrel SK, Molinari J. Aerosols and splatter in Dentistry: a brief review of the literature and infection control implications. J Am Dent Assoc. 2004;135:429.

24. Suresh S, Manimegalai S, Sudhakar U, Sophia S. Comparison of efficacy of preprocedural rinsing with chlorhexidine and essential oil mouthwash in reducing viable bacteria in dental aerosols-a microbiological study . Int J Contemp Dent. 2011;2(6):1-6.

25. Reddy S, Prasad MGS, Kaul S, Satish K. Efficacy of 0.2\% tempered chlorhexidine as a preprocedural mouth rinse: A clinical study. J Indian Soc Periodontol. 2012;16(2):213-7.

26. Kaur R, Singh I, Vandana KL, Desai R. Effect of chlorhexidine, povidone iodine, and ozone on microorganisms in dental aerosols: Randomized double-blind clinical trial. Indian J Dent Res. 2014;25(2):160.

27. Centers for Disease Control and Prevention, Guidelines for infection control in dental health - care settings - 2003, MMWR 2003; 53(No RR17): Pg 18-9. 